\title{
A Cross-Sectional Study to Examine Factors Associated with Primary Health Care Service Utilization among Older Adults in the Irbid Governorate of Jordan
}

\author{
Abdullah Alkhawaldeh, ${ }^{1}$ Margo B. Holm, ${ }^{2}$ Jamal Qaddumi, ${ }^{3}$ \\ Wasileh Petro, ${ }^{4}$ Madi Jaghbir, ${ }^{5}$ and Omar Al Omari ${ }^{1}$ \\ ${ }^{1}$ Faculty of Nursing and Midwifery, Jerash University, Amman, Irbid International Street, Jerash 26150, Jordan \\ ${ }^{2}$ Faculty of Health and Rehabilitation Sciences, University of Pittsburgh, Pittsburgh, PA 15260, USA \\ ${ }^{3}$ Faculty of Medicine and Health Sciences, An-Najah National University, P.O. Box 7, Nablus, Palestine \\ ${ }^{4}$ Faculty of Nursing, Jordan University, Amman 11942, Jordan \\ ${ }^{5}$ Faculty of Medicine, Jordan University, Amman 11942, Jordan
}

Correspondence should be addressed to Abdullah Alkhawaldeh; dr-abd@jpu.jo

Received 27 June 2014; Revised 8 October 2014; Accepted 12 October 2014; Published 6 November 2014

Academic Editor: Tomasz Kostka

Copyright (C) 2014 Abdullah Alkhawaldeh et al. This is an open access article distributed under the Creative Commons Attribution License, which permits unrestricted use, distribution, and reproduction in any medium, provided the original work is properly cited.

Background. Recently, the percentage of older adults in developing countries has increased significantly. Objective. This study examined patterns and factors associated with primary health care services utilization in the past 1, 6, and 12 months. Method. A cross-sectional study design was used to collect data from 190 older adults in the Irbid governorate of Jordan. Results. Primary health care services were used by less than half of the participants in the past 1 month, by $68.4 \%$ in the past 6 months, and by $73.8 \%$ in the past 12 months. Primary health care (PHC) services use was associated with age, education level, tobacco use, chronic illnesses, perceived general health status today, a physical component summary score, employment, and perceived general health status in the past 6 and 12 months. The primary predictor of PHC services use at 1,6, and 12 months was chronic illnesses $(\mathrm{OR}=13.32)$, $(\mathrm{OR}=19.63)$, and $(\mathrm{OR}=17.91)$, respectively. Conclusion. Although many factors were associated with PHC service utilization, the strongest predictor of PHC service utilization was chronic illnesses.

\section{Introduction}

Recently, the percentage of older adults in developing countries has increased significantly [1]. Middle income countries have found that this increase in older adults represents a major challenge for health care organizations as a result of the physical, social, and psychological changes associated with complex morbidity and mortality profiles [2]. Subsequently, all countries need to be prepared to address the consequences of the demographic trends associated with aging populations. Worldwide, the increasing health care demand of older persons requires a better understanding of factors influencing health care service utilization patterns [3]. In several parts of the developing world, primary health care
(PHC) use is inadequately understood [4]. In Jordan, there is an inadequate amount of reliable data existing on health care utilization rates and thus health care planners are unable to estimate accurately the real needs of the population [5].

Some studies have explored health services utilization patterns across several countries [6-8]. A study of older Estonians found that about 81 percent indicated having visited a general practitioner or specialist during the prior 1 year [9]. Similarly, health service utilization among older Nigerians was high, finding that $95.3 \%$ had visited a health care facility and $90.3 \%$ reported being sick frequently; however, just 67.8 percent visited a health facility once they were critically sick [6]. In contrast, health service use among older Chinese in the past 6 months was less than 50 percent and consisted 
of general outpatient clinic services (36.7\%) and specialist outpatient clinic services (20.8\%) [7]. Similarly, health care services use in the past 1 month among older adults in Hong Kong was less than 50 percent and the services were provided by Western medicine physicians (both generalists and specialists) in a Government clinic (31.1\%), private physicians of Western medicine (11.1\%), practitioners of Chinese medicine (2.5\%), and Western medicine practitioners in emergency units $(1.9 \%)$ [8]. In Spain, researchers found that, of the health care services utilized by $74.5 \%$ of older adults in the past 3 months, $18.4 \%$ were nursing staff visits, $59.4 \%$ were general practitioner visits, and $16.5 \%$ were specialist visits [10].

Patterns in health services utilization by older adults have been found to be associated with many factors [7-13]. For example, among 787 older adults over 64 years of age in Spain, health service contacts were greater for females than males. Moreover, educational level was negatively associated with outpatient services, chronic diseases, and medication use. Additionally, poorer health status was positively associated with general practitioner consultations, smoking was negatively associated with health care use, and older adults with depression or the perceived need for care were associated with greater health care use. In Spain, the significant predictors of general practitioner use were perceived need for care, selfreported health status, and educational level [10]. In Hong Kong, a study found that age was significantly associated with hospital use, income was significantly associated with both general and specialist outpatient clinic services utilization, and family instrumental care was significantly associated with hospital use. Self-rated health status and particular kinds of chronic illness were significantly associated with use of the four services. Also, poorer activities of daily living scores were associated with both emergency room and general outpatient clinic use, and greater symptoms of depression were associated with hospital use [7].

A study conducted in Ghana reported that health care utilization was associated with participants' age group, occupation, medical history of chronic conditions, cognitive impairment in past 30 days, and self-reported health status. In addition, significant predictors were age group, medical history of chronic condition, cognitive impairment, selfperceived health, and difficulty with picking up items in the past 30 days [13]. In Korea, a study found that those most likely to have used long-term care services were 80 years and older, had less than 13 years of education, lived with others, were religious, had no income and health insurance, had poor health status, and had activities of daily living/instrumental activities of daily living (ADL/IADL) limitations and cognitive impairment. Determinants of long-term care services use were health status, ADL/IADL limitations, and cognitive impairments [12]. A Thai study found that greater health care services utilization in the past year, among 504 adults aged 60 and older, was associated with older males [11]. The utilization of health care services was also connected with married, less educated participants, and diagnoses with a chronic illness [11].

Although there were some studies that studied health status of older adults in Jordan [14-19], a comprehensive literature review revealed a dearth of research regarding factors that influence PHC service use among older adults in Jordan. Hence, this study aimed to examine patterns and factors associated with PHC utilization by Jordanians aged 50 years and older living in the Irbid governorate of north Jordan.

\section{Materials and Methods}

2.1. Design. A cross-sectional study design was used to examine PHC services utilization patterns and to identify factors associated with and predictive of health care utilization/nonutilization in the past 1,6 , and 12 months. The study was conducted in the catchment areas associated with three comprehensive PHC centers which provide services from 8 a.m. to 4 p.m., and most of these health centers serve large numbers of people and offer many preventive and curative health care services situated in areas within the Irbid governorate of north Jordan [20].

2.2. Participants. Adequate sample size needed for binary logistic regression [21] was determined using the formula proposed by Peduzzi et al. [22]. They suggested a minimum $N$ that is at least 10 times $K$, where $K$ is the number of predictors in the model. Using their criteria, the minimum sample size needed for this study was 190 participants.

A proportional convenience sample of 190 older adults, aged 50 and older, participated in this study from three areas (south $(n=79)$, center $(n=85)$, and north $(n=26))$ of the Irbid governorate in Jordan (Irbid is the third largest inhibited city). These primary health care centers serve around 69,088 inhabitants.

\subsection{Measures}

2.3.1. Dependent Variables. PHC service utilization in the past 1,6 , and 12 months.

Participants were asked the following. Did you visit the primary health care center in your region during the past month? Past 6 months? Past 12 months?

2.3.2. Independent Variables. Based on Anderson's behavioral model, predisposing, enabling, and need factors were included as follows [23]: predisposing factors included age (years), gender (male or female), health behavior measuring tobacco use (smoker or nonsmoker), employment status (unemployed, retired, and employed), education level (no education, primary school, and secondary), and marital status (married, single, separated or divorced, and widowed). Enabling factors included monthly income and health insurance coverage (insured or not insured). Need factors included chronic illness self-reports (have/do not have a chronic illness).

Additionally, cognitive impairment was measured by using the Elderly Cognitive Assessment Questionnaire (ECAQ) [24]. Perceived general health was measured in two ways: (1) on a scale of 1 to 10 , with a 1 representing the "worst I have ever felt" and a 10 representing the "best I have ever felt." What number would best represent your general health 
today? 6 months ago? 12 months ago? And (2) perceived general health status in the past 1-month period was measured using the 12-Item Short Form Health Survey version 2 (SF12v2) [25]. SF-12v2 measures eight health domains: physical function, role-physical, bodily pain, general health, vitality, social functioning, role-emotional, and mental health. These domains are summarized as physical component summary (PCS) and mental component summary (MCS) scales and use norm-based scoring. When the scores are transformed, the general population has a mean of 50 and a standard deviation of 10 . So, when compared to the general population, health related quality of life (HRQOL) is considered to be lower than the norm if PCS or MCS scores are calculated to be lower than 50 [25].

2.4. Data Analysis. Descriptive statistics were used to describe study variables. Chi-square associations with categorical variables and Pearson correlations were conducted to establish associations between independent and dependent variables and to identify which variables would enter logistic regression model. Correlation tests included were Spearman's rho, Point Biserial $r$, Phi coefficient $(\phi)$, and Cramer's V and were used depending on the level of measurement for each variable. Three binary logistic regression models were developed for utilization/nonutilization of $\mathrm{PHC}$ services during the past 1,6 , and 12 months. The probability $(P<0.05)$ was taken as minimum level of significance.

2.5. Ethical Considerations. Permission for conducting study was obtained from the University Of Jordan School Of Nursing and the Jordan Ministry of Health Ethical Committee. Permission to use the ECQA instrument was obtained from the instrument developer and permission to use the Algerian (Arabic) SF-12v2 was obtained from Quality Metric Incorporated (License agreement CT130430/OP011094). All participants were notified that the data collected would be treated with anonymity and confidentiality. In addition, personal informed verbal consent was obtained from all participants.

\section{Results}

3.1. Participants. Table 1 depicts participants' characteristics. The mean age of participants was 64.6 years $(\mathrm{SD}=9.7)$. There were more male $(57.4 \%)$ participants, and the majority of participants were married (88.4\%). About $36.8 \%$ of participants had no formal education, although 42.1 percent of the participants received a primary school education and 21.1 percent received a secondary education or higher. Most of the participants were unemployed (55.3\%) and nonsmokers (71.1\%). The majority (93.7\%) had some type of health insurance coverage. The mean monthly income per participant was 218.2 Jordanian Dinars. About $72.1 \%$ of participants had chronic illnesses and $96.8 \%$ showed no evidence of cognitive impairment. For perceived general health status on the SF$12 \mathrm{v} 2$ for the past 1 month, the mean physical component summary (PCS) score was $41.28(\mathrm{SD}=11.0)$ and 50.46 (SD $=7.3$ ) for the mental component summary (MCS) score. For
TABLE 1: Descriptive statistics of the predisposing, enabling, and need variables of older adult participants $(n=190)$.

\begin{tabular}{|c|c|c|}
\hline Variables & $\%$ & $\begin{array}{l}\text { Mean } \\
\text { (S.D.) }\end{array}$ \\
\hline \multicolumn{3}{|l|}{ Predisposing variables } \\
\hline Age (in years) & & $\begin{array}{l}64.6 \\
(9.7)\end{array}$ \\
\hline \multicolumn{3}{|l|}{ Gender } \\
\hline Male & 57.4 & \\
\hline Female & 42.6 & \\
\hline \multicolumn{3}{|l|}{ Marital status } \\
\hline Married & 88.4 & \\
\hline Widow & 11.6 & \\
\hline \multicolumn{3}{|l|}{ Education level } \\
\hline No education & 36.8 & \\
\hline Primary school education & 42.1 & \\
\hline Secondary and higher education & 21.1 & \\
\hline \multicolumn{3}{|l|}{ Employment status } \\
\hline Unemployed & 55.3 & \\
\hline Retired & 41.1 & \\
\hline Employed & 3.7 & \\
\hline \multicolumn{3}{|l|}{ Tobacco user } \\
\hline Nonsmoker & 71.1 & \\
\hline Smoker & 28.9 & \\
\hline \multicolumn{3}{|l|}{ Enabling variables } \\
\hline \multicolumn{3}{|l|}{ Health insurance } \\
\hline Uninsured & 6.3 & \\
\hline Insured & 93.7 & \\
\hline Income (Jordanian Dinars per month) & & $\begin{array}{r}218.2 \\
(88.7) \\
\end{array}$ \\
\hline \multicolumn{3}{|l|}{ Need variables } \\
\hline \multicolumn{3}{|l|}{ Chronic illnesses } \\
\hline No chronic illnesses & 27.9 & \\
\hline Have chronic illnesses & 72.1 & \\
\hline \multicolumn{3}{|l|}{ Cognitive impairment } \\
\hline No cognitive impairment & 96.8 & \\
\hline Have cognitive impairment & 3.2 & \\
\hline Perceived general health status today & & $\begin{array}{l}6.61 \\
(1.3)\end{array}$ \\
\hline \multicolumn{3}{|l|}{$\begin{array}{l}\text { Perceived general health status in the } \\
\text { last } 1 \text { month }\end{array}$} \\
\hline PCS score & & $\begin{array}{l}41.28 \\
(11.0)\end{array}$ \\
\hline MCS score & & $\begin{array}{c}50.46 \\
(7.3)\end{array}$ \\
\hline $\begin{array}{l}\text { Perceived general health status in the } \\
\text { past } 6 \text { months }\end{array}$ & & $\begin{array}{l}6.46 \\
(1.3)\end{array}$ \\
\hline $\begin{array}{l}\text { Perceived general health status in the } \\
\text { past } 12 \text { months }\end{array}$ & & $\begin{array}{l}6.64 \\
(1.3)\end{array}$ \\
\hline
\end{tabular}

perceived general health status today, in the past 6 and 12 months, the means were $6.61(\mathrm{SD}=1.3), 6.46(\mathrm{SD}=1.3)$, and $6.64(\mathrm{SD}=1.3)$, respectively. 
TABLE 2: Factors associated with primary health care services utilization of older adults in the past 1,6 , and 12 months.

\begin{tabular}{|c|c|c|c|}
\hline Variable & $\begin{array}{c}\text { Utilization } \\
1 \text { month }\end{array}$ & $\begin{array}{l}\text { Utilization } \\
6 \text { months }\end{array}$ & $\begin{array}{l}\text { Utilization } \\
12 \text { months }\end{array}$ \\
\hline \multicolumn{4}{|l|}{ Predisposing variables } \\
\hline Age & 0.134 & $0.229^{* *}$ & $0.205^{* *}$ \\
\hline Gender & -0.093 & -0.105 & -0.100 \\
\hline Marital status & 0.129 & 0.069 & 0.017 \\
\hline Education level & $-0.220^{* *}$ & $-0.200^{* *}$ & $-0.240^{* *}$ \\
\hline Employment status & 0.158 & $0.178^{*}$ & $0.218^{* *}$ \\
\hline Tobacco use & $-0.162^{*}$ & $-0.166^{*}$ & $-0.145^{*}$ \\
\hline \multicolumn{4}{|l|}{ Enabling variables } \\
\hline Health insurance & 0.087 & 0.056 & 0.002 \\
\hline Income & -0.135 & -0.073 & -0.111 \\
\hline \multicolumn{4}{|l|}{ Need variables } \\
\hline Chronic illnesses & $0.453^{* *}$ & $0.663^{* *}$ & $0.650^{* *}$ \\
\hline Cognitive impairment & -0.030 & 0.058 & 0.034 \\
\hline $\begin{array}{l}\text { Perceived general } \\
\text { health status today }\end{array}$ & $-0.272^{* *}$ & $-0.355^{* *}$ & $-0.373^{* *}$ \\
\hline \multicolumn{4}{|l|}{$\begin{array}{l}\text { Perceived general } \\
\text { health status in last } 1 \\
\text { month: }\end{array}$} \\
\hline PCS score & $-0.377^{* *}$ & - & - \\
\hline MCS score & -0.106 & & \\
\hline $\begin{array}{l}\text { Perceived general } \\
\text { health status in last } 6 \\
\text { months }\end{array}$ & - & $-0.409^{* *}$ & - \\
\hline $\begin{array}{l}\text { Perceived general } \\
\text { health status in the } \\
\text { last } 12 \text { months }\end{array}$ & - & - & $-0.306^{* *}$ \\
\hline
\end{tabular}

${ }^{*}$ Correlation is significant at the 0.05 level (2-tailed).

${ }^{* *}$ Correlation is significant at the 0.01 level (2-tailed).

3.2. Older Adult PHC Services Utilization Patterns. In the past 1,6 , and 12 months, 41 percent of participants used medical services in the past 1 month. In the past 6 months, 68.4 percent of participants had used medical services, and in the past 12 months, 73.8 percent of participants had used medical services.

\subsection{Factors Associated with Older Adults' PHC Services Utilization}

3.3.1. In the Past 1-Month Period. Participants who used significantly more PHC services in the past month were those who (a) had no formal education or had a primary school education, (b) were nonsmokers, (c) had a chronic illness, (d) had perceptions of poorer health status, and (e) had symptoms or poor physical health (lower SF-12v2 PCS score) (see Table 2).

3.3.2. In Past 6-Month Period. Factors significantly associated with increased use of PHC services were (a) increasing age, (b) being unemployed or retired, (c) having no formal education or only a primary school education, (d) being nonsmokers, (e) having a chronic illness, (f) those having poor self-rated general health status today, and (g) those having a poor self-rated general health status in the past 6 months (see Table 2).

3.3.3. In Past 12-Month Period. Significantly greater use of PHC services was associated with (a) increasing age, (b) being unemployed or retired, (c) having no formal education or only a primary school education, (d) being nonsmokers, (e) having a chronic illness, (f) those having poor self-rated general health status today, and (g) those having poor selfrated general health status in the past 12 months (see Table 2).

3.4. Factor That Predicted Primary Health Care Service Utilization. The variable associated with PHC services utilization in the past 1-, 6-, and 12-month period was chronic illness (OR 13.324, 95\% CI 3.614-49.128), (OR 19.634, CI 7.67950.203), and (OR 17.915, 95\% CI 6.974-0.023), respectively (see Table 3).

\section{Discussion}

4.1. Utilization Patterns. For older adults in three catchment areas of the Irbid governorate of Jordan, data on medical services utilization in the past 1,6 , and 12 months were not consistent. The findings showed that rate of medical services use by older adults in the past one month was less than $50 \%$, which was consistent with a study in Hong Kong [8]. In the past 6 months, the findings showed that two-thirds of older adults used PHC services for medical health services, which differed from rates reported by Chou and Chi [7] study. In the past 12 months, the findings indicated that three-quarters of older adults used PHC services for medical health services, which is close to the Estonian study [9]. The high rate of medical service utilization in past 12 months compared with rate of utilization in the past 6-month and 1-month periods in the present study can be accounted for by the use of a longer time period. This would have increased the chances of including those who rarely used PHC services. Further studies need to be conducted on the utilization of more and different types of health care service in the changing health care context.

\subsection{Factors Associated with PHC Service Utilization}

4.2.1. Predisposing Factors. In the present study, older age was not associated with PHC service utilization in the past 1 month, similar to that found in Spain [10]; however, older age was positively associated with $\mathrm{PHC}$ service utilization in the past 6 and 12 months. In contrast, older age in Thailand was associated with fewer health care services use in the past year [11]. Lower education level was associated with greater PHC service utilization in the past 1, 6, and 12 months, which was also found in other studies $[10,11]$. Those who were unemployed or retired used more PHC services than those employed in the past 6 and 12 months. As limited PHC literature includes older adults, employment status was 
TABLE 3: Binary logistic regression analysis of predictors of primary health care service utilization of older adults in the past 1,6 , and 12 months.

\begin{tabular}{|c|c|c|c|c|c|c|c|c|c|}
\hline & \multicolumn{3}{|c|}{$\begin{array}{l}\text { PHC service utilization } \\
\text { in the past } 1 \text { month }\end{array}$} & \multicolumn{3}{|c|}{$\begin{array}{l}\text { PHC service utilization } \\
\text { in the past } 6 \text { months }\end{array}$} & \multicolumn{3}{|c|}{$\begin{array}{l}\text { PHC service utilization } \\
\text { in the past } 12 \text { months }\end{array}$} \\
\hline & \multirow{2}{*}{ OR } & \multicolumn{2}{|c|}{ CIs } & \multirow{2}{*}{ OR } & \multicolumn{2}{|c|}{ CIs } & \multirow{2}{*}{ OR } & \multicolumn{2}{|c|}{ CIs } \\
\hline & & Lower & Upper & & Lower & Upper & & Lower & Upper \\
\hline \multicolumn{10}{|l|}{ Predisposing factors } \\
\hline Age & 0.98 & 0.94 & 1.02 & 1.00 & 0.95 & 1.05 & 0.97 & 0.92 & 1.03 \\
\hline \multicolumn{10}{|l|}{ Education level } \\
\hline No education & 1.37 & 0.37 & 5.03 & 0.76 & 0.14 & 4.00 & 3.26 & 0.56 & 18.80 \\
\hline Primary education & 0.66 & 0.24 & 1.82 & 0.45 & 0.13 & 1.51 & 1.50 & 0.44 & 5.07 \\
\hline $\begin{array}{l}\text { Secondary and higher } \\
\text { education }{ }^{\#}\end{array}$ & 1.00 & - & - & 1.00 & - & - & 1.00 & - & - \\
\hline \multicolumn{10}{|l|}{ Employment status } \\
\hline Unemployed & 1.49 & 0.11 & 19.59 & 1.99 & 0.20 & 19.5 & 2.62 & 0.23 & 29.02 \\
\hline Retired & 1.40 & 0.11 & 17.40 & 1.82 & 0.20 & 16.1 & 4.57 & 0.44 & 47.19 \\
\hline Employed $^{\wedge}$ & 1.00 & - & - & 1.00 & - & - & 1.00 & - & - \\
\hline Tobacco use & 0.78 & 0.34 & 1.77 & 0.78 & 0.30 & 2.03 & 0.83 & 0.30 & 2.30 \\
\hline \multicolumn{10}{|l|}{ Need factors } \\
\hline Chronic illnesses & $13.3^{* *}$ & 3.61 & 49.12 & $19.6^{* *}$ & 7.67 & 50.2 & $17.9^{* *}$ & 6.97 & 0.02 \\
\hline Perceived general health today & 0.92 & 0.67 & 1.26 & 1.03 & 0.61 & 1.75 & 0.65 & 0.42 & 1.03 \\
\hline PCS score & 0.97 & 0.93 & 1.02 & & & & & & \\
\hline $\begin{array}{l}\text { Self-perceived general health in } \\
\text { the past } 6 \text { months }\end{array}$ & & & & 0.66 & 0.37 & 1.17 & & & \\
\hline $\begin{array}{l}\text { Self-perceived general health in } \\
\text { the past } 12 \text { months }\end{array}$ & & & & & & & 0.96 & 0.62 & 1.48 \\
\hline \multicolumn{10}{|c|}{$\begin{array}{l}{ }^{*} \text { Reference group. } \\
{ }^{\wedge} \text { Reference group. } \\
\text { Note. PCS: physical component summary score of SF-12v2. } \\
\text { OR: odds ratio. } \\
\text { CIs: } 95 \% \text { confidence interval. } \\
{ }^{* *} \text { OR statistics is significant at the } 0.001 \text { level. }\end{array}$} \\
\hline
\end{tabular}

among the factors not included in many studies. However, similar results were observed in Ghana [13]. Nonsmoking older adults used more PHC services in the past 1,6 , and 12 months compared with smokers. This result was consistent with a previous study [10].

4.2.2. Needs Factors. Chronic illness was significantly associated with PHC service utilization in the past 1,6 , and 12 months, consistent with studies in Thailand and Spain $[10,11]$. Cognitive impairment was not associated with PHC service utilization in the past 1,6 , and 12 months which is in contrast to earlier findings $[12,13]$. This disagreement may be attributed to the fact that only $3.2 \%$ of the sample had cognitive impairment in this study and due to different measures being used across studies. The perceived general health status factors were found to be negatively associated with PHC service utilization, indicating that participants who perceived that they were in poor health on the day of the interview tended to use more PHC services during the past 1,6 , and 12 months. One explanation may be that older adults, especially those who have chronic illnesses, tend to go to health centers mainly to obtain their prescribed medication. Also, both aging and many chronic illnesses are associated with disabilities and complications that are difficult to manage without utilizing health services. Also, chronicity does not portend improvement over a 1-year time period.

Further studies need to be conducted to confirm that perceived general health status today correlates with PHC service utilization of older adults. Also, those older adults who perceived that they were in poor health, in particular, poorer physical health (PCS score) in the past 1 month, tended to use more PHC services in the past 1 month. This result disagrees with previous studies $[10,13]$. Older adults who perceived that they were in poor general health status in the past 6 and 12 months used more PHC services in those time periods and this has been found previously [10].

4.3. Predictors of PHC Services Use in the Past 1, 6, and 12 Months. Age was not a significant predictor of PHC services utilization in the past 1,6 , and 12 months, in contrast to a study in Ghana [13], and education level was not a significant predictor of PHC services utilization in the past 1,6 , and 12 months, which was similar to a South Korean study [12], and 
neither was employment status a significant predictor of $\mathrm{PHC}$ services utilization in the past 1,6 , and 12 months, consistent with the findings by [13]. Likewise, tobacco use was not a significant predictor of PHC services utilization in the past 1,6 , and 12 months, similar to a Spanish study [10].

Chronic illness was the strongest significant predictor of PHC services utilization in the past 1,6 , and 12 months. Multivariate analysis indicated that older adults who had chronic illnesses were 13.3, 19.6, and 17.9 times more likely to use PHC services than those who did not have chronic illnesses in the past 1, 6, and 12 months, respectively. This finding is consistent with another study [7]. The findings in this study can be explained by the fact that the majority of the older adults who used PHC services in the past 1,6 , and 12 months had at least one chronic illness, and chronic illnesses need continuous treatment. These data are important for planning purposes for the PHC service centers and suggest that patients with one or more chronic illnesses should be identified so that the PHC can be responsive to their continuous needs.

Perceived general health today was not a significant predictor of PHC services utilization in the past 1,6 , and 12 months. Likewise, the PCS score was not a significant predictor of $\mathrm{PHC}$ services utilization in the past 1 month. This finding diverges from a prior study [7]. One justification for this difference could be related to differences in measures that were used to assess the self-evaluation of physical health and to differences in recall periods in assessing the utilization.

4.4. Limitations. Health care services use, history of chronic illnesses, and perceived health status of participants were selfreported. However, several attempts were made to reduce the possibility of recall bias: (a) the study used different recall periods (1, 6, and 12 months), (b) PHC services use and history of chronic illnesses were measured as a dichotomous variable, which is easier to recall, and (c) the study participants were community dwelling older adults with a relatively low frequency of cognitive impairment (about 3.2\% had evidence of cognitive impairment based on the ECAQ) [24]. Also, the results cannot be generalized to PHC services in other governorates or in the entire country.

\section{Conclusion}

About three-fourths of older adults in this study reported having at least one chronic illness. Hence, there was an unusually high rate of chronic illness among the participants in this study. In terms of utilization patterns, the findings reflected high utilization rates of PHC services among older adults over a one-year period. The present study identified several predisposing and need factors that were associated with $\mathrm{PHC}$ service utilization. However, the strongest predictor of $\mathrm{PHC}$ service utilization was a medical history of chronic illnesses.

The results of this study add to the body of knowledge in geriatric nursing regarding older adults' health seeking behavior which will help in developing an effective nursing care programs to promote well-being in Jordanian older adults. Good health care planning requires an understanding of PHC service use, and the approach used in this study could be replicated throughout Jordan. As such, it would enable the Ministry of Health in Jordan to gather relevant data necessary to provide appropriate health care services for older adults that are both efficient and cost-effective. Moreover, such data could help planning for healthier lifestyles throughout the life course and to build comprehensive and preventative health care programs in the PHC centers that will promote better health for older adults, instead of the current focus on cure and/or medication prescriptions.

\section{Conflict of Interests}

The authors declare that there is no conflict of interests regarding the publication of this paper.

\section{References}

[1] L. J. Dominguez, A. Galioto, A. Ferlisi et al., "Ageing, lifestyle modifications, and cardiovascular disease in developing countries," Journal of Nutrition, Health and Aging, vol. 10, no. 2, pp. 143-149, 2006.

[2] World Health Organization, Innovative Care for Chronic Conditions: Building Blocks for Action, WHO Library Cataloging, 2002.

[3] M. I. de Cordova, N. Mier, E. J. M. Curi, T. G. Gómez, N. H. G. Quirarte, and F. F. Barrios, "Personal and social determinants of health services utilization by Mexican older people," International Journal of Older People Nursing, vol. 5, no. 3, pp. 193-201, 2010.

[4] J. B. Baker and L. Liu, "The determinants of primary health care utilization: a comparison of three rural clinics in Southern Honduras," GeoJournal, vol. 66, no. 4, pp. 295-310, 2006.

[5] High Health Council, "Jordan National Health Account. High health council," 2007, https://www.healthresearchweb.org/en/ jordan/institution_381.

[6] J. Agbogidi and C. Azodo, "Experiences of the elderly utilizing healthcare services in Edo state," The Internet Journal of Geriatrics and Gerontology, vol. 5, no. 2, 2009.

[7] K. L. Chou and I. Chi, "Factors associated with the use of publicly funded services by Hong Kong Chinese older adults," Social Science and Medicine, vol. 58, no. 6, pp. 1025-1035, 2004.

[8] H.-K. Yam, S. W. Mercer, L.-Y. Wong, W.-K. Chan, and E.$\mathrm{K}$. Yeoh, "Public and private healthcare services utilization by non-institutional elderly in Hong Kong: is the inverse care law operating?” Health Policy, vol. 91, no. 3, pp. 229-238, 2009.

[9] K. Põlluste, R. Kalda, and M. Lember, "Accessibility and use of health services among older Estonian population," Central European Journal of Public Health, vol. 17, no. 2, pp. 64-70, 2009.

[10] C. Fernández-Olano, J. D. L.-T. Hidalgo, R. Cerdá-Díaz et al., "Factors associated with health care utilization by the elderly in a public health care system," Health Policy, vol. 75, no. 2, pp. 131139, 2006.

[11] M. F. Villacorta, Health Services Utilization Among the Thai Elderly: Findings from the Kanchanaburi Project Demographic Surveillance Survey, Mahidol University, 2003.

[12] J. M. Park, "The determinants of long-term care utilization and equity of access to care among older adults in Dong-Ku of Incheon Metropolitan City, South Korea," Asia-Pacific Journal of Public Health, vol. 17, no. 2, pp. 104-109, 2005. 
[13] A. Exavery, Determinants of Health Care Utilisation Among The Elderly Population In Rural Ghana, University of the Witwatersrand, Johannesburg, South Africa, 2010.

[14] I. Taani, Analysis of the Health Situation of the Elderly in the City of Irbid, Jordan University of Science and Technology, 1995.

[15] W. I. Petro-Nustas, "Factors associated with mammography utilization among Jordanian women," Journal of Transcultural Nursing, vol. 12, no. 4, pp. 284-291, 2001.

[16] F. S. Hasna, "Utilization of family planning services in the Governorate of Zarqa, Jordan," Journal of Transcultural Nursing, vol. 17, no. 4, pp. 365-374, 2006.

[17] B. Ekman, "The impact of health insurance on outpatient utilization and expenditure: evidence from one middle-income country using national household survey data," Health Research Policy and Systems, vol. 5, article 6, 2007.

[18] S. M. Alkhaldi, Maternal Health Care Utilization in Rural Jordanian Villages: Patterns and Predictors, ProQuest, 2008.

[19] M. A. Alhusban and R. F. Abualrub, "Patient satisfaction with nursing care in Jordan," Journal of Nursing Management, vol. 17, no. 6, pp. 749-758, 2009.

[20] Jordanian Ministry of Health, Health Information, and Ministry of Health, 2013, http://www.moh.gov.jo/en/Pages/default .aspx.

[21] R. M. Warner, Applied Statistics: From Bivariate Through Multivariate Techniques, Sage, Thousand Oaks, Calif, USA, 2008.

[22] P. Peduzzi, J. Concato, E. Kemper, T. R. Holford, and A. R. Feinstem, "A simulation study of the number of events per variable in logistic regression analysis," Journal of Clinical Epidemiology, vol. 49, no. 12, pp. 1373-1379, 1996.

[23] R. Andersen, A behavioral Model of Families' Use of Health Services, vol. 25 of Research Series, Center for Health Administration Studies, University of Chicago, Chicago, Ill, USA, 1968.

[24] E. H. Kua and S. M. Ko, "A questionnaire to screen for cognitive impairment among elderly people in developing countries," Acta Psychiatrica Scandinavica, vol. 85, no. 2, pp. 119-122, 1992.

[25] J. E. Ware Jr., M. Kosinski, and S. D. Keller, "A 12-Item ShortForm Health Survey: construction of scales and preliminary tests of reliability and validity," Medical Care, vol. 34, no. 3, pp. 220-233, 1996. 


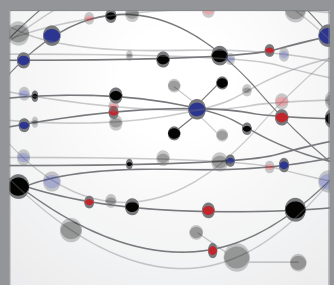

The Scientific World Journal
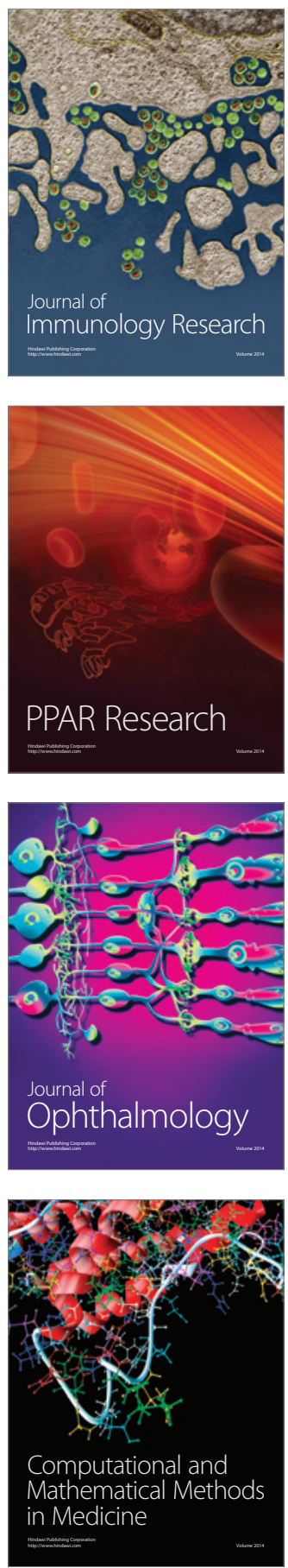

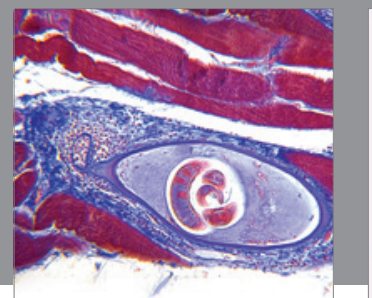

Gastroenterology

Research and Practice
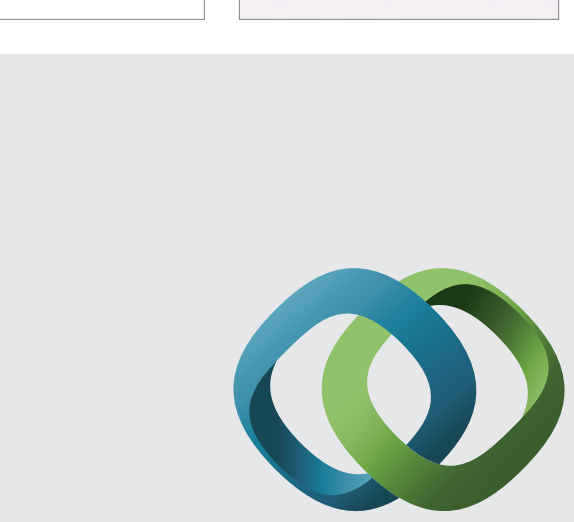

\section{Hindawi}

Submit your manuscripts at

http://www.hindawi.com
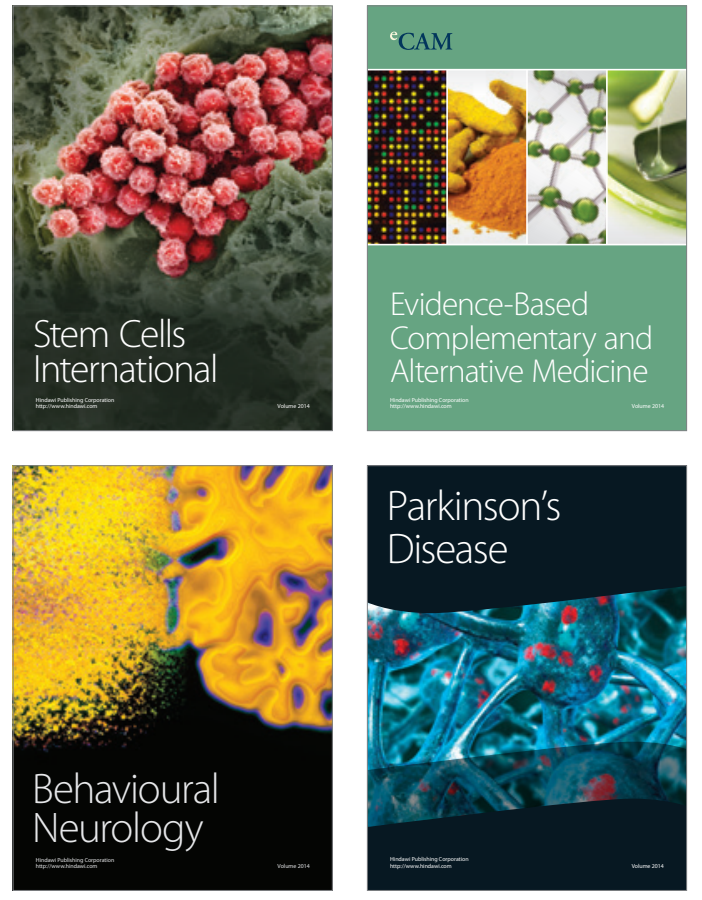
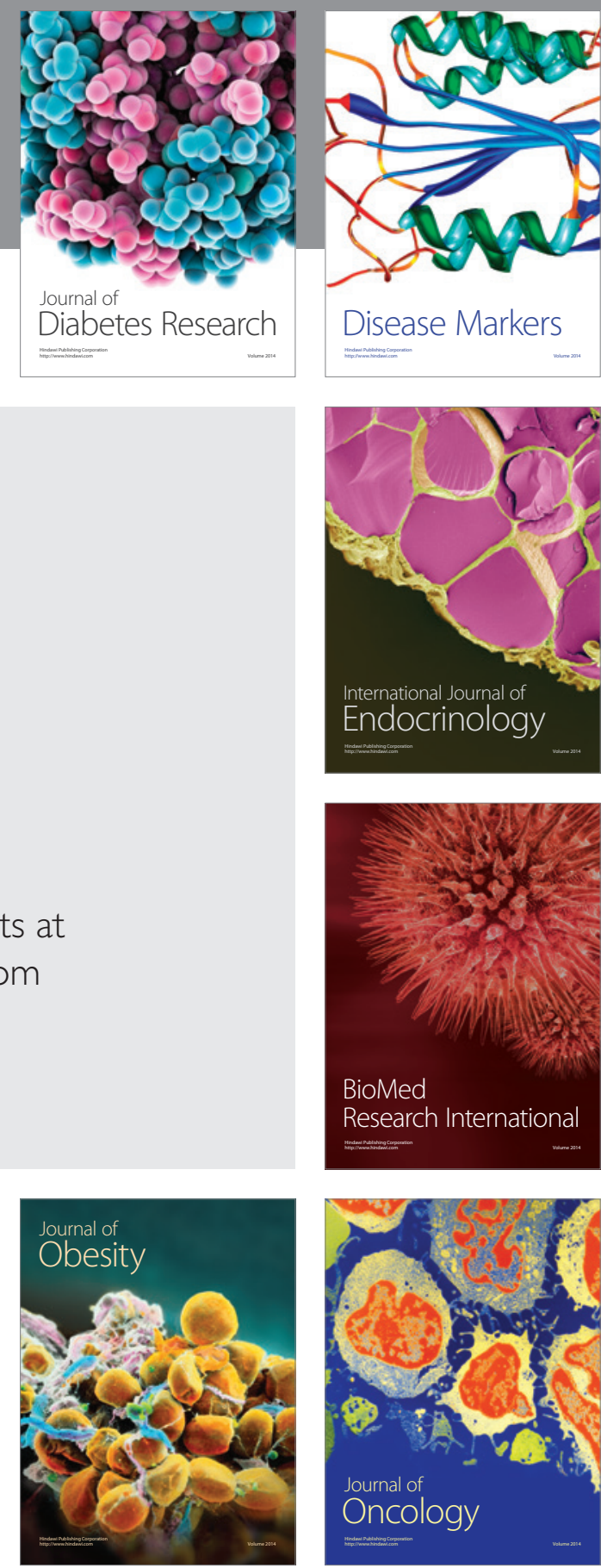

Disease Markers
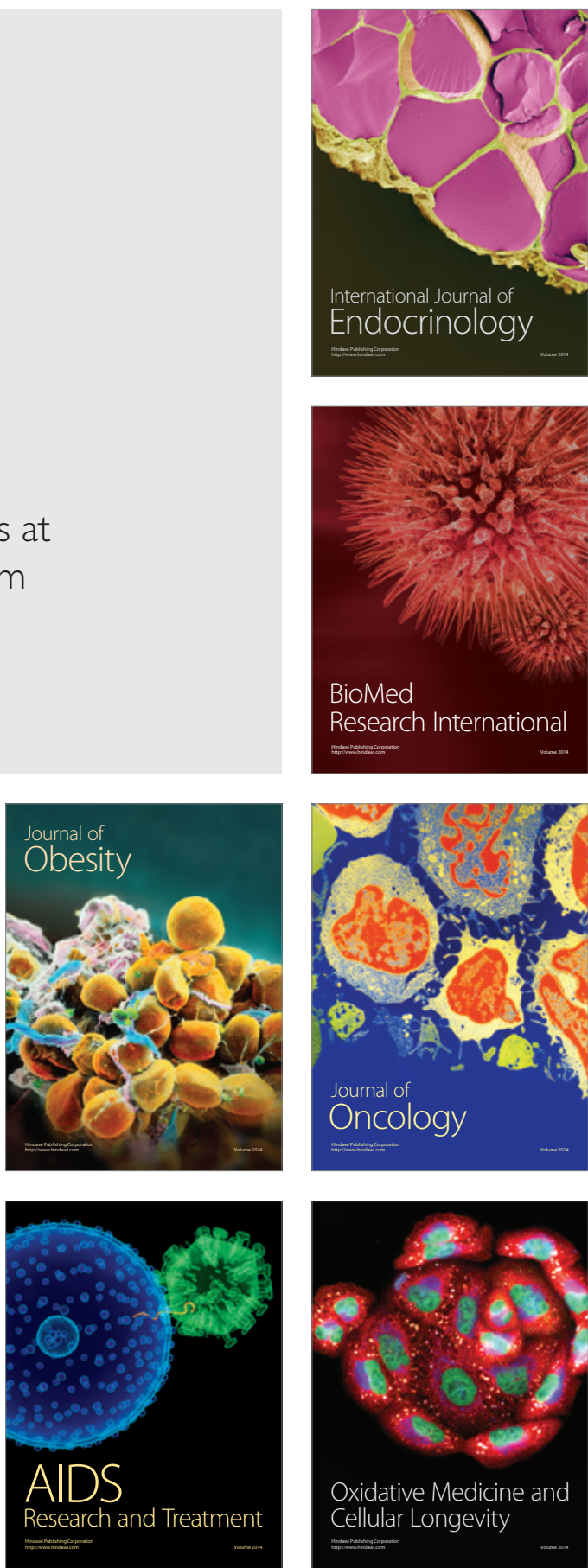